\title{
A Mathematical Model of MMT (Modern Monetary Theory) with Profit Return
}

\author{
Yasuhito Tanaka \\ Faculty of Economics, Doshisha University, Kamigyo-ku, Kyoto, 602-8580, Japan \\ E-mail: yatanaka@mail.doshisha.ac.jp
}

Received: September 27, 2021 Accepted: November 1, 2021 Published: November 4, 2021

doi:10.5296/ber.v11i4.19142ＵRL: https://doi.org/10.5296/ber.v11i4.19142

\begin{abstract}
Even in perfect competition there is a positive profit return if the good is produced with decreasing returns to scale technology. Using a two-periods overlapping generations (OLG) model with production under perfect competition with decreasing returns to scale technology in which the economy grows by technological progress and the older generation consumers receive the profit returns, we consider the problem of budget deficit under economic growth. We will show the following results. 1) We need a budget deficit to achieve full employment under constant price when the economy grows by technological progress. 2) If the budget deficit exceeds the level necessary to maintain full employment in a growing economy under constant price, inflation will be triggered. We need a stable budget deficit to prevent further inflation. 3) If the budget deficit is insufficient to maintain full employment, it will cause a recession with involuntary unemployment. We can overcome a recession and restore full employment caused by insufficient budget deficit by a budget deficit larger than the one necessary and sufficient to maintain full employment without a recession. We should not offset the deficit created to overcome the recession by subsequent surpluses because we can maintain full employment through constant budget deficits. Also, we show that in each case the budget deficit equals the difference between the net savings of the younger generation consumers and that of the older generation consumers.
\end{abstract}

Keywords: MMT, Economic growth, Budget deficit, Decreasing returns to scale, Profit return

JEL Classification: E12, E24

\section{Introduction}

In previous studies we examined the arguments for fiscal policy by Functional Finance Theory of Lerner (1943, 1944) and MMT (Modern Monetary Theory, Wray (2015), Mitchell, 
Wray and Watts (2019), Kelton (2020)) ${ }^{1}$ using a static model or an overlapping generations model with production under perfect competition with constant returns to scale technology. In a model of perfect competition under constant returns to scale there is no profit of firms. In order to include the existence of corporate profits in the analysis, it is possible to consider the case of production using not only labor but also capital, or to use a monopolistic competition model, but this paper deals with a simple model of perfect competition under decreasing returns to scale. While maintaining the basics of the neoclassical microeconomic framework, such as consumers' utility maximization through utility functions and budget constraints, and equilibrium of supply and demand of goods, the idea of the effect of fiscal policy, which is the backbone of the functional finance theory and MMT discussions, is actively discussed using a simple mathematical model.

We use a two-periods (or two-generations) overlapping generations (OLG) model with production in perfectly competitive industry with decreasing returns to scale technology in which the economy grows by technological progress and the older generation consumers receive the profit returns, and we will prove the following results.

1) We need a budget deficit to achieve and maintain full employment under constant price when the economy grows by technological progress. (Section 2)

2) If the budget deficit exceeds the level necessary and sufficient to achieve and maintain full employment in a growing economy under constant price, inflation will be triggered. We need a continuous budget deficit to prevent further inflation. (Section 3)

3) If the budget deficit is insufficient to achieve and maintain full employment, it will cause a recession with involuntary unemployment. (Section 4)

We can overcome a recession and restore full employment caused by insufficient budget deficit by a budget deficit larger than the one necessary and sufficient to maintain full employment without a recession. We should not offset the deficit created to overcome the recession by subsequent surpluses because we can maintain full employment through continuous budget deficits. We consider restoration of full employment by fiscal spending (Section 5) and by tax reduction (Sections 6 and 7).

Also, we show that in each case the budget deficit equals the difference between the net savings of the younger generation consumers and that of the older generation consumers. The net savings means the consumptions of consumers in their older period (the second period) net of the profit returns which are received in their older period.

We think that the essence of MMT with respect to fiscal policy lies in the following two points.

1. "Taxes are not a source of revenue for fiscal spending", or "fiscal spending does not require financial resources"

1 Other references are Shimakura (2019), Mochizuki (2020), Morinaga (2020), Nakano (2020) and Park (2020). These are introductory texts of MMT written in Japanese. 
From a macroeconomic perspective, fiscal spending serves to increase the demand for goods, while taxes serve to reduce demand by reducing people's disposable income. In order to achieve full employment and stable growth without inflation, the size of fiscal spending and taxes must be adjusted, not those taxes are necessary for fiscal spending (the content of fiscal spending and the fairness of taxes are important but separate issues).

2. There is no need to pay off government debt with taxes.

Although not discussed specifically in this paper, all government bonds could be redeemed tomorrow without raising taxes if it wanted to (although it does not have to). The central bank could just buy them all up. This may have the effect of lowering interest rates, but it will not directly increase demand for goods and will not cause high-rate inflation because people's assets will not increase (unless the central bank buys them at prices above face value) and they will not generate income. If it is done during a recession, low-rate inflation will not occur either. Since government bonds are also money in the same broad sense as bank time deposits ("liquidity in the broad sense"), and since the central bank's purchase of government bonds does not increase the money supply in that sense, inflation does not occur even from the perspective of the Quantity Theory of Money.

\section{Economic Growth and Budget Deficit}

We use a two-periods (generations) overlapping generations (OLG) model. It is a simplified version of the model by Otaki $(2007,2009,2015)$. We assume that the good is produced in the perfectly competitive industry although Otaki considered monopolistic competition. Consumers live over two-periods, the younger period (the first period) and the older period (the second period). They work only in the younger period. They consume the good in the older period by their savings carried over from their younger period and the profit returns received from firms. The ratio of consumption of the consumers in their younger period is $\alpha$, and that in the older period is $1-\alpha$. We assume $\frac{1}{2}<\alpha<1$. $\alpha$ is the marginal propensity to consume. These values are obtained by utility maximization of consumers by, for example, the Cobb-Douglas utility function about consumptions in the younger period and the older period.

There is one good produced in perfectly competitive industry with decreasing returns to scale technology. The labor productivity is $\mathrm{y}$. It is a decreasing function of the employment $\mathrm{L}$. Denote it by $y(L)$. The economy grows by technological progress. The labor productivity increases at the rate $\gamma-1>0$ from period to period. The nominal wage rate $w$ also increases at the rate $\gamma-1$ under constant price. In a period, Period 1, it is $y$. Now consider the profit maximization of the representative firm. The number of firms is normalized to one. Let $p$ be the price of the good. The profit of a firm is

$$
\pi=p y(L) L-w L=p y(L) L-w L .
$$

The condition for profit maximization is

$$
\frac{\partial \pi}{\partial L}=p\left(y+y^{\prime} L\right)-w=p y\left(1+\frac{y^{\prime} L}{y}\right)-w=0 .
$$


Let

$$
\eta=-\frac{y^{\prime} L}{y}>0
$$

Then,

$$
p y(1-\eta)-w=0
$$

This means

$$
p=\frac{1}{1-\eta} \frac{w}{y}
$$

$\eta$ is the (minus of the) elasticity of the labor productivity. By the decreasing returns to scale, $y^{\prime}<0$ and $\eta$ is positive. We assume that it is smaller than one. If $w=y$,

$$
p=\frac{1}{1-\eta}
$$

Since $0<\eta<1, p>1$. The profit of a firm is

$$
\pi=p y L-w L=\frac{1}{1-\eta} w L-w L=\frac{\eta}{1-\eta} w L>0 .
$$

The profits of firms are positive. In the next period (Period 2) the labor productivity increases at the rate of $\gamma-1$. Thus, the profit of a firm in that period is

$$
\frac{\eta}{1-\eta} \gamma w L
$$

Note that $\gamma w$ is the nominal wage rate (without inflation) in Period 2. Denote the profit return which is received by an older generation consumer in Period 2 by $\Pi_{2}$. Let $L_{f}$ be the labor supply, or employment in the full employment state. Then,

$$
\Pi_{2}=\frac{\eta}{1-\eta} \gamma w \frac{L}{L_{f}} .
$$

For simplicity we assume that every older generation consumer receives the profit return including consumers who were unemployed in their younger period. Of course, we can assume that only the older generation consumers who were employed in their younger period receive the profit returns. Basically, the result is the same.

We suppose full employment in this section. Thus,

$$
\Pi_{2}=\frac{\eta}{1-\eta} \gamma w
$$

Let $G$ and $T$ be the government expenditure and the (total) tax in Period 1. The younger generation consumers pay the taxes. Suppose $w=y$. The savings of the younger generation consumers in Period 1 is 


$$
(1-\alpha)\left(y L_{f}+\Pi_{2} L_{f}-T\right)
$$

This is equal to the consumption of the older generation consumers in Period 2. Since they receive the profit returns in the next period, their net savings is

$$
(1-\alpha)\left(y L_{f}+\Pi_{2} L_{f}-T\right)-\Pi_{2} L_{f}=(1-\alpha)\left(y L_{f}-T\right)-\alpha \Pi_{2} L_{f} .
$$

The government expenditure and the tax in Period 2 are $\gamma G$ and $\gamma T$. The consumption of the younger generation consumers in Period 2 is

$$
\alpha\left(\gamma y L_{f}+\Pi_{3} L_{f}-\gamma T\right)=\alpha \gamma\left(y L_{f}+\Pi_{2} L_{f}-T\right) .
$$

$\Pi_{3}$ is the profit received by an older generation consumer in Period 3. Under full employment

$$
\Pi_{3}=\frac{\eta}{1-\eta} \gamma^{2} y=\gamma \Pi_{2} .
$$

The net savings of the younger generation consumers is

$$
(1-\alpha) \gamma\left(y L_{f}+\Pi_{2} L_{f}-T\right)-\gamma \Pi_{2} L_{f}=(1-\alpha) \gamma\left(y L_{f}-T\right)-\gamma \alpha \Pi_{2} L_{f} .
$$

The nominal total supply in Period 2 is

$$
\gamma p y L_{f} .
$$

The nominal total demand is

$$
\alpha \gamma\left(y L_{f}+\Pi_{2} L_{f}-T\right)+(1-\alpha)\left(y L_{f}+\Pi_{2} L_{f}-T\right)+\gamma G .
$$

From the equilibrium between the total supply and the total demand, we get

$$
\gamma p y L_{f}=\alpha \gamma\left(y L_{f}+\Pi_{2} L_{f}-T\right)+(1-\alpha)\left(y L_{f}+\Pi_{2} L_{f}-T\right)+\gamma G .
$$

From this

$$
\gamma y L_{f}=\alpha \gamma\left(y L_{f}+\Pi_{2} L_{f}-T\right)+(1-\alpha)\left(y L_{f}+\Pi_{2} L_{f}-T\right)+\gamma G-\gamma(p-1) y L_{f} .
$$

Since $p=\frac{1}{1-\eta}$ and $\Pi_{2}=\frac{\eta}{1-\eta} \gamma y$,

$$
\gamma y L_{f}=\alpha \gamma\left(y L_{f}+\Pi_{2} L_{f}-T\right)+(1-\alpha)\left(y L_{f}+\Pi_{2} L_{f}-T\right)+\gamma G-\Pi_{2} L_{f} .
$$

Then, 


$$
\begin{gathered}
\gamma(G-T)=\gamma(1-\alpha)\left(y L_{f}-T\right)-(1-\alpha)\left(y L_{f}-T\right)-(1-\alpha) \Pi_{2} L_{f}-\alpha \gamma \Pi_{2} L_{f}+\Pi_{2} L_{f} \\
=(\gamma-1)\left[(1-\alpha)\left(y L_{f}-T\right)-\alpha \Pi_{2} L_{f}\right] .
\end{gathered}
$$

(2) implies that if $\gamma>1$, the budget deficit should be positive, and that the budget deficit equals the difference between the net savings of the younger generation consumers and the net savings of the older generation consumers.

Summarizing the results,

Proposition 1 We need a budget deficit to achieve and maintain full employment with economic growth under constant price even if there are profit returns for the older generation consumers. The budget deficit equals the difference between the net savings of the younger generation consumers and that of the older generation consumers.

This budget deficit should not be offset by future surplus so long as the economy grows under constant price because we need stable budget deficit to maintain full employment under constant price in a growing economy.

In this section we assume that the consumers save by money. It can be shown that similar conclusions can be reached if savings are not made in money but in government bonds issued by the government and interest is paid on them. From calculations in Appendix,

$$
\begin{aligned}
\gamma(G-T)+r\left[(1-\alpha)\left(y L_{f}-T\right)-\alpha \frac{\Pi_{2} L_{f}}{1+r}\right]=\gamma\left[(1-\alpha)\left(y L_{f}-T\right)-\alpha \frac{\Pi_{2} L_{f}}{1+r}\right] \\
-\left[(1-\alpha)\left(y L_{f}-T\right)-\alpha \frac{\Pi_{2} L_{f}}{1+r}\right] .
\end{aligned}
$$

This means that the budget deficit including the interest payment for the government bonds equals the difference between the net savings of the younger generation consumers and that of the older generation consumers.

In the following sections we assume that the consumers save by money.

\section{Inflation by Excess Budget Deficit}

Let $\xi p$ be the price of the good in Period 2, the nominal wage rate be $\xi \gamma y$, the government expenditure be $\zeta G$. Assume that excess budget deficit and inflation in Period 2 were not predicted by the older generation consumers in Period 1 (their younger period), and the younger generation consumers think that the price in Period 3 is the same as the price in Period $2^{2}$. The profit return for an older generation consumer is

\footnotetext{
${ }^{2}$ If the older generation consumers had predicted inflation in Period 2 when they were younger, this would have affected their consumption in Period 1, and complicated effects would have arisen, such as changing the size of the budget deficit at which full employment should be achieved at a given price, but it would not have changed the fact that an excessive budget deficit in Period 2 would have caused inflation.
} 


$$
\Pi_{2}^{\prime}=\frac{\eta}{1-\eta} \gamma \xi y=(p-1) \gamma \xi y=\xi \Pi_{2}
$$

We assume that the nominal value of the tax is $\gamma T$. The nominal total supply in Period 2 is

$$
\xi p \gamma y L_{f} \text {. }
$$

The profit return in the next period for a younger generation consumer is

$$
\Pi_{3}{ }^{\prime}=\gamma \Pi_{2}{ }^{\prime} \text {. }
$$

The consumption of the older generation consumers is

$$
(1-\alpha)\left(y L_{f}+\Pi_{2} L_{f}-T\right)+(\xi-1) \Pi_{2} L_{f}
$$

Their net savings is

$$
\begin{gathered}
(1-\alpha)\left(y L_{f}+\Pi_{2} L_{f}-T\right)+(\xi-1) \Pi_{2} L_{f}-\Pi_{2} L_{f}-(\xi-1) \Pi_{2} L_{f} \\
=(1-\alpha)\left(y L_{f}-T\right)-\alpha \Pi_{2} L_{f} .
\end{gathered}
$$

The consumption of the younger generation consumers is

$$
\alpha \gamma\left(\xi y L_{f}+\xi \Pi_{2} L_{f}-T\right)
$$

Their net savings is

$$
(1-\alpha) \gamma\left(\xi y L_{f}+\xi \Pi_{2} L_{f}-T\right)-\gamma \xi \Pi_{2} L_{f}=(1-\alpha) \gamma\left(\xi y L_{f}-T\right)-\gamma \alpha \xi \Pi_{2} L_{f} .
$$

The nominal total demand is

$$
\alpha \gamma\left(\xi y L_{f}+\xi \Pi_{2} L_{f}-T\right)+(1-\alpha)\left(y L_{f}+\Pi_{2} L_{f}-T\right)+(\xi-1) \Pi_{2} L_{f}+\zeta G .
$$

From the equilibrium between the total supply and the total demand, we obtain

$$
\xi p \gamma y L_{f}=\alpha \gamma\left(\xi y L_{f}+\xi \Pi_{2} L_{f}-T\right)+(1-\alpha)\left(y L_{f}+\Pi_{2} L_{f}-T\right)+(\xi-1) \Pi_{2} L_{f}+\zeta G .
$$

From this

$$
\begin{gathered}
\xi \gamma y L_{f}=\alpha \gamma\left(\xi y L_{f}+\xi \Pi_{2} L_{f}-T\right)+(1-\alpha)\left(y L_{f}+\Pi_{2} L_{f}-T\right) \\
+(\xi-1) \Pi_{2}+\zeta G-\xi \gamma(p-1) y L_{f} .
\end{gathered}
$$

Since $p=\frac{1}{1-\eta}$ and $\Pi_{2}=(p-1) \gamma y$, we get

$$
\xi \gamma y L_{f}=\alpha \gamma\left(\xi y L_{f}+\xi \Pi_{2} L_{f}-T\right)+(1-\alpha)\left(y L_{f}+\Pi_{2} L_{f}-T\right)+\zeta G+(\xi-1) \Pi_{2} L_{f}-\xi \Pi_{2} L_{f} .
$$


Then,

$$
\begin{gathered}
\zeta G-\gamma T=\gamma(1-\alpha)\left(\xi y L_{f}-T\right)-(1-\alpha)\left(y L_{f}-T\right)-(1-\alpha) \Pi_{2} L_{f}-\alpha \gamma \xi \Pi_{2} L_{f}+\Pi_{2} L_{f} \\
\quad=\gamma\left[(1-\alpha)\left(\xi y L_{f}-T\right)-\alpha \xi \Pi_{2} L_{f}\right]-\left[(1-\alpha)\left(y L_{f}-T\right)-\alpha \Pi_{2} L_{f}\right]
\end{gathered}
$$

This is the difference between the net savings of the younger generation consumers and that of the older generation consumers. Comparing this with (2),

$$
(\zeta G-\gamma T)-\gamma(G-T)=(1-\alpha)\left[\gamma\left(\xi y L_{f}-T\right)-\gamma\left(y L_{f}-T\right)\right]-\gamma \alpha \xi \Pi_{2} L_{f}+\gamma \alpha \Pi_{2} L_{f} .
$$

This is rewritten as

$$
(\zeta-\gamma) G=(\xi-1)\left[(1-\alpha) \gamma y L_{f}-\gamma \alpha \Pi_{2} L_{f}\right] .
$$

When $(\zeta G-\gamma T)-\gamma(G-T)=(\zeta-\gamma) G>0$, we have $\xi>1$. This means inflation in Period 2. Summarizing the results in the following proposition,

Proposition 2 A budget deficit (given $\operatorname{tax}^{3}$ ) that exceeds the level necessary to maintain full employment in a growing economy under constant price will cause inflation.

As for the process leading to inflation, we can think of a story in which excess demand for goods generates excess demand for labor, which raises the nominal wage rate, which in turn raises the price of the goods. Assuming that production does not increase above the full employment level, nominal supply and demand will not be balanced unless the price rises.

(3) means that even in this case the budget deficit equals the difference between the net savings of the younger generation consumers and that of the older generation consumers.

The relation between $\zeta$ and $\xi$ given $\xi>1$ is

$$
\frac{\zeta-\gamma}{\xi-1}=\frac{\gamma\left[(1-\alpha) y L_{f}-\alpha \Pi_{2} L_{f}\right]}{G} .
$$

We need a stable budget deficit discussed in the previous section to prevent further inflation.

\section{Recession and Involuntary Unemployment by Insufficient Budget Deficit}

Let $L$ be the employment in Period 2. Assume that the government expenditure is $\zeta G$, the tax is $\gamma T$. The price of the good is constant. The profit return for an older generation consumer is

\footnotetext{
3 A change in fiscal spending and that in tax have different effects on the national income. An increase in fiscal spending and tax while keeping the budget deficit constant will lead to inflation, while a decrease in fiscal spending and tax while keeping the budget deficit constant will lead to a recession. It is because the multiplier of a change in tax is smaller than that of a change in fiscal spending. On the other hand, a change in tax influences on consumption of the older generation consumers in the next period.
} 


$$
\Pi_{2}=\frac{\eta}{1-\eta} \gamma y \frac{L}{L_{f}}
$$

If full employment will be restored in Period 3, the profit return in the next period for a younger generation consumer is

$$
\Pi_{3}=\frac{\eta}{1-\eta} \gamma^{2} y
$$

The nominal total supply in Period 2 is

$$
\text { rpyL. }
$$

The consumption of the older generation consumers is

$$
(1-\alpha)\left(y L_{f}+\Pi_{2} L_{f}-T\right)
$$

Their net savings is

$$
(1-\alpha)\left(y L_{f}+\Pi_{2} L_{f}-T\right)-\Pi_{2} L_{f}=(1-\alpha)\left(y L_{f}-T\right)-\alpha \Pi_{2} L_{f} .
$$

The consumption of the younger generation consumers is

$$
\alpha\left(\gamma y L+\Pi_{3} L_{f}-\gamma T\right)
$$

Their net savings is

$$
(1-\alpha)\left(\gamma y L+\Pi_{3} L_{f}-\gamma T\right)-\gamma \Pi_{3} L_{f}=(1-\alpha)(\gamma y L-\gamma T)-\alpha \Pi_{3} L_{f} .
$$

The nominal total demand is

$$
\alpha\left(\gamma y L+\Pi_{3} L_{f}-\gamma T\right)+(1-\alpha)\left(y L_{f}+\Pi_{2} L_{f}-T\right)+\zeta G .
$$

From the equilibrium between the total supply and the total demand,

$$
\gamma p y L=\alpha\left(\gamma y L+\Pi_{3} L_{f}-\gamma T\right)+(1-\alpha)\left(y L_{f}+\Pi_{2} L_{f}-T\right)+\zeta G .
$$

This means

$$
\begin{gathered}
\zeta G-\gamma T=\gamma(1-\alpha)(y L-T)-(1-\alpha)\left(y L_{f}-T\right)-\alpha \Pi_{3} L_{f}-(1-\alpha) \Pi_{2} L_{f} \\
+(p-1) \gamma y L .
\end{gathered}
$$

Since $p=\frac{1}{1-\eta}$ and $\Pi_{2}=\frac{\eta}{1-\eta} \gamma y \frac{L}{L_{f}}$, we obtain 


$$
\zeta G-\gamma T=\left[\gamma(1-\alpha)(y L-T)-\alpha \Pi_{3} L_{f}\right]-\left[(1-\alpha)\left(y L_{f}-T\right)-\alpha \Pi_{2} L_{f}\right] .
$$

This is the difference between the net savings of the younger generation consumers and that of the older generation consumers. Assume that $\Pi_{3}$ in (4) equals $\gamma \Pi_{2}$ in (2). Comparing (4) with (2),

$$
\begin{aligned}
& (\zeta G-\gamma T)-\gamma(G-T)=\zeta G-\gamma G=(1-\alpha)\left[\gamma(y L-T)-\gamma\left(y L_{f}-T\right)\right] \\
& =(1-\alpha) \gamma\left(L-L_{f}\right) .
\end{aligned}
$$

When $(\zeta G-\gamma T)-\gamma(G-T)=\zeta G-\gamma G<0, L<L_{f} \quad$ is derived. Then, there is involuntary unemployment ${ }^{4}$. Summarizing the results, we obtain

Proposition 3 A budget deficit (given $\operatorname{tax}^{5}$ ) that is insufficient to maintain full employment will cause a recession with involuntary unemployment.

(4) means that even in this case the budget deficit equals the difference between the net savings of the younger generation consumers and that of the older generation consumers.

In this section, we assume that the nominal wage rate is constant. But, in contrast to the case of inflation, an insufficient demand for goods may cause an insufficient demand for labor, which lowers the nominal wage rate and lowers the price. If the price falls, the real value of the savings of the older generation consumers will increase, and the real balance effect (the so-called Pigou effect) may increase consumption and employment, but it is commonly believed that this effect will not be large at least in the short run. In this case, fiscal policy, which we will discuss in the next section, can overcome the recession more quickly than a fall in the nominal wage rate. In the case of inflation, the increase in nominal demand cannot be absorbed without an increase in prices unless production and employment increase beyond full employment levels, whereas in the case of insufficient demand, the nominal wage rate may remain constant and production and employment may decrease.

\section{Recovery from Recession by the Government Expenditure}

We will recover full employment in Period 3. Suppose that the taxes in Periods 2 and 3 are $\gamma T$ and $\gamma^{2} T$. The total supply is

$$
\gamma^{2} p y L_{f}
$$

The profit return for an older generation consumer is denoted by

$$
\Pi_{3}=\frac{\eta}{1-\eta} \gamma^{2} y
$$

\footnotetext{
${ }^{4}$ About involuntary unemployment please see Hattori and Tanaka (2020).

5 Please see footnote 2.
} 


\section{Macrothink}

The profit return for a younger generation consumer is

$$
\Pi_{4}=\frac{\eta}{1-\eta} \gamma^{3} y=\gamma \Pi_{3}
$$

The consumption (or the savings) of the older generation consumers is

$$
(1-\alpha)\left[\gamma(y L-T)+\Pi_{3} L_{f}\right]
$$

Their net savings is

$$
(1-\alpha)\left[\gamma(y L-T)+\Pi_{3} L_{f}\right]-\Pi_{3} L_{f}=(1-\alpha) \gamma(y L-T)-\alpha \Pi_{3} L_{f} .
$$

The consumption of the younger generation consumers is

$$
\alpha\left[\gamma^{2}\left(y L_{f}-T\right)+\gamma \Pi_{3} L_{f}\right]
$$

Their net savings is

$$
(1-\alpha)\left[\gamma^{2}\left(y L_{f}-T\right)+\gamma \Pi_{3} L_{f}\right]-\gamma \Pi_{3} L_{f}=(1-\alpha) \gamma^{2}\left(y L_{f}-T\right)-\alpha \gamma \Pi_{3} L_{f} .
$$

Let $\zeta G$ be the government expenditure. The total demand is

$$
\alpha\left[\gamma^{2}\left(y L_{f}-T\right)+\gamma \Pi_{3} L_{f}\right]+(1-\alpha)\left[\gamma(y L-T)+\Pi_{3} L_{f}\right]+\zeta G .
$$

Note that $L$ is employment in Period 2. From the equilibrium between the total supply and the total demand, we have

$$
\gamma^{2} p y L_{f}=\alpha\left[\gamma^{2}\left(y L_{f}-T\right)+\gamma \Pi_{3} L_{f}\right]+(1-\alpha)\left[\gamma(y L-T)+\Pi_{3} L_{f}\right]+\zeta G .
$$

On the other hand, if there is no recession, in Period 3 (1) means

$$
\gamma^{2} p y L_{f}=\alpha\left[\gamma^{2}\left(y L_{f}-T\right)+\gamma \Pi_{3} L_{f}\right]+(1-\alpha)\left[\gamma\left(y L_{f}-T\right)+\Pi_{3} L_{f}\right]+\gamma^{2} G
$$

By (5) and (6),

$$
\zeta G-\gamma^{2} G=(1-\alpha) \gamma y\left(L_{f}-L\right)
$$

When $L<L_{f}$, we have $\zeta>\gamma^{2}$. Therefore, a larger budget deficit is required than would be required to maintain full employment in the absence of a recession. From (5) we obtain

$$
\begin{gathered}
\zeta G-\gamma^{2} T=(1-\alpha) \gamma^{2}\left(y L_{f}-T\right)-(1-\alpha) \gamma(y L-T)-\alpha \gamma \Pi_{3} L_{f} \\
-(1-\alpha) \Pi_{3} L_{f}+(p-1) \gamma^{2} y L_{f} .
\end{gathered}
$$


Since $\quad p=\frac{\eta}{1-\eta}$ and $\Pi_{3}=\frac{\eta}{1-\eta} \gamma^{2} y$, this means

$$
\zeta G-\gamma^{2} T=(1-\alpha) \gamma^{2}\left(y L_{f}-T\right)-\alpha \gamma \Pi_{3} L_{f}-\left[(1-\alpha) \gamma(y L-T)-\alpha \Pi_{3} L_{f}\right]
$$

Summarizing the results, we obtain

Proposition 4 A budget deficit larger than the one necessary and sufficient to maintain full employment without a recession can overcome a recession caused by insufficient budget deficit and restore full employment.

(7) means that even in this case the budget deficit equals the difference between the net savings of the younger generation consumers and that of the older generation consumers.

We should not offset the deficit created to overcome the recession by subsequent surpluses because we need a stable budget deficit to maintain full employment with economic growth under constant price.

\section{Recovery from Recession by the Tax Reduction}

Again, we will recover full employment in Period 3. Suppose that the government expenditures in Periods 2 and 3 are $\gamma G$ and $\gamma^{2} G$. As in the previous case the profit return for an older generation consumer is denoted by

$$
\Pi_{3}=\frac{\eta}{1-\eta} \gamma^{2} y
$$

The profit return for a younger generation consumer is

$$
\Pi_{4}=\frac{\eta}{1-\eta} \gamma^{3} y=\gamma \Pi_{3}
$$

The nominal total supply is

$$
\gamma^{2} p y L_{f}
$$

The consumption (or the savings) of the older generation consumers is

$$
(1-\alpha)\left(\gamma y L+\Pi_{3} L_{f}-\gamma T\right)
$$

Their net savings is

$$
(1-\alpha)\left(\gamma y L+\Pi_{3} L_{f}-\gamma T\right)-\Pi_{3} L_{f}=(1-\alpha)(\gamma y L-\gamma T)-\alpha \Pi_{3} L_{f}
$$

Let $\eta T$ be the tax in Period 3. Then, the consumption of the younger generation consumers is

$$
\alpha\left(\gamma^{2} y L_{f}+\gamma \Pi_{3} L_{f}-\eta T\right)
$$


Their net savings is

$$
(1-\alpha)\left(\gamma^{2} y L_{f}+\gamma \Pi_{3} L_{f}-\eta T\right)-\gamma \Pi_{3} L_{f}=(1-\alpha)\left(\gamma^{2} y L_{f}-\eta T\right)-\alpha \gamma \Pi_{3} L_{f} .
$$

The total demand is

$$
\alpha\left(\gamma^{2} y L_{f}+\gamma \Pi_{3} L_{f}-\eta T\right)+(1-\alpha)\left(\gamma y L+\Pi_{3} L_{f}-\gamma T\right)+\gamma^{2} G
$$

Note that $L$ is employment in Period 2. From the equilibrium between the total supply and the total demand, we have

$$
\gamma^{2} p y L_{f}=\alpha\left(\gamma^{2} y L_{f}+\gamma \Pi_{3} L_{f}-\eta T\right)+(1-\alpha)\left(\gamma y L+\Pi_{3} L_{f}-\gamma T\right)+\gamma^{2} G
$$

Again, if there is no recession, (6) holds in Period 3. By (6) and (8),

$$
\alpha\left(\gamma^{2}-\eta\right) T=(1-\alpha) \gamma y\left(L_{f}-L\right)
$$

When $L<L_{f}$, we get $\eta<\gamma^{2}$. Therefore, a larger budget deficit by tax reduction is required than would be required to maintain full employment in the absence of a recession. From (8) we obtain

$$
\begin{gathered}
\gamma^{2} G-\eta T=(1-\alpha)\left(\gamma^{2} y L_{f}-\eta T\right)-(1-\alpha) \gamma(y L-T)-\alpha \gamma \Pi_{3} L_{f} \\
-(1-\alpha) \Pi_{3} L_{f}+(p-1) \gamma^{2} y L_{f} .
\end{gathered}
$$

Since $p=\frac{\eta}{1-\eta}$ and $\Pi_{3}=\frac{\eta}{1-\eta} \gamma^{2} y$, this means

$$
\gamma^{2} G-\eta T=(1-\alpha)\left(\gamma^{2} y L_{f}-\eta T\right)-\alpha \gamma \Pi_{3} L_{f}-\left[(1-\alpha) \gamma(y L-T)-\alpha \Pi_{3} L_{f}\right]
$$

Summarizing the results, we obtain

Proposition 5 A budget deficit larger than the one necessary and sufficient to maintain full employment without a recession can overcome a recession caused by insufficient budget deficit and restore full employment by tax reduction.

(10) means that even in this case the budget deficit equals the difference between the net savings of the younger generation consumers and that of the older generation consumers.

\section{Concluding Remark}

Using a two-periods overlapping generations (OLG) model with production of the good under perfect competition with decreasing returns to scale technology and profit returns to older generation consumers, we have shown that excessive budget deficits lead to inflation, 
but budget deficits are necessary and useful for economic growth and overcoming recessions. Although in this paper we assume a decreasing returns to scale technology under perfect competition in order to derive the existence of profit, similar conclusions may be drawn by considering monopolistic competition producing differentiated goods.

In the future, we would like to attempt to analyse budget deficits in an economy that produces goods using both capital and labor as factors of production.

\section{Acknowledgment}

We thank the reviewers for their thorough reviews and highly appreciate the comments and suggestions, which significantly contributed to improving the quality of the publication. This work was supported by JSPS KAKENHI Grant Number 18K01594 in Japan.

\section{Appendix: Savings by government bonds not money}

We consider a case where the consumers save not in money but in government bonds. A younger generation consumer is either employed or unemployed. Assume the existence of unemployment insurance for consumers who are unemployed. Let $C_{1}^{e}, C_{2}^{e}$ be consumptions of an employed consumer in Period 2 in his younger and older periods. Then, his budget constraint is

$$
(1+r) C_{1}^{e}+C_{2}^{e}=(1+r)\left(\gamma y-\gamma \frac{T}{L}-\Theta\right)+\Pi_{3}
$$

$r$ is the interest rate of the government bond. $\Theta$ is the tax for the unemployment insurance. $L$ is employment. We assume that only employed consumers pays the tax. We can assume that even unemployed consumer as well as an employed consumer pays the tax. The results are the same. The budget constraint for an unemployed consumer is

$$
(1+r) C_{1}^{u}+C_{2}^{u}=(1+r) R+\Pi_{3} .
$$

$R$ is the unemployment insurance. By maximization of consumers' utility for homothetic utility functions such as $\alpha \ln C_{1}^{e}+(1-\alpha) \ln C_{2}^{e}$ (for employed consumer) we obtain

$$
\begin{gathered}
C_{1}^{e}=\alpha\left[\left(\gamma y-\gamma \frac{T}{L}-\Theta\right)+\frac{\Pi_{3}}{1+r}\right], \\
C_{2}^{e}=(1-\alpha)\left[(1+r)\left(\gamma y-\gamma \frac{T}{L}-\Theta\right)+\Pi_{3}\right], \\
C_{1}^{u}=\alpha\left(R+\frac{\Pi_{3}}{1+r}\right), \\
C_{2}^{u}=(1-\alpha)\left[(1+r) R+\Pi_{3}\right] .
\end{gathered}
$$

Since $L \Theta=\left(L_{f}-L\right) R$, the total consumption of the younger generation consumers in Period 2 is

$$
L C_{1}^{e}+\left(L_{f}-L\right) C_{1}^{u}=\alpha\left(\gamma y L-\gamma T+\frac{\Pi_{3}}{1+r} L_{f}\right)=\alpha \gamma\left(y L-T+\frac{\Pi_{2} L_{f}}{1+r}\right) .
$$


Their consumption in their older period is

$$
(1-\alpha) \gamma\left[(1+r)(y L-T)+\Pi_{2} L_{f}\right]
$$

and their net savings (in their younger period) is

$$
(1-\alpha) \gamma(y L-T)-\alpha \gamma \frac{\Pi_{2} L_{f}}{1+r}
$$

Similarly, the total consumption of the older generation consumers in Period 2 is

$$
(1-\alpha)\left[(1+r)(y \bar{L}-T)+\Pi_{2} L_{f}\right]
$$

Their net savings (in their younger period) is

$$
(1-\alpha)(y \bar{L}-T)-\alpha \frac{\Pi_{2} L_{f}}{1+r} .
$$

$\bar{L}$ is the employment in the previous period (Period 1). Assume full employment. Then, the total demand in Period 2 is

$$
\alpha \gamma\left(y L_{f}-T+\frac{\Pi_{2} L_{f}}{1+r}\right)+(1-\alpha)\left[(1+r)\left(y L_{f}-T\right)+\Pi_{2} L_{f}\right]+\gamma G .
$$

The equilibrium of the total supply and the total demand is represented by

$$
\gamma p y L_{f}=\alpha \gamma\left(y L_{f}-T+\frac{\Pi_{2} L_{f}}{1+r}\right)+(1-\alpha)\left[(1+r)\left(y L_{f}-T\right)+\Pi_{2} L_{f}\right]+\gamma G .
$$

From this we get

$$
\begin{aligned}
\gamma y L_{f}=\alpha \gamma\left(y L_{f}-T+\right. & \left.\frac{\Pi_{2} L_{f}}{1+r}\right)+(1-\alpha)\left[(1+r)\left(y L_{f}-T\right)+\Pi_{2} L_{f}\right] \\
& +\gamma G-\gamma(p-1) y L_{f} .
\end{aligned}
$$

Since $p=\frac{1}{1-\eta}$ and $\Pi_{2}=\frac{\eta}{1-\eta} \gamma y$,

$$
\gamma y L_{f}=\alpha \gamma\left(y L_{f}-T+\frac{\Pi_{2} L_{f}}{1+r}\right)+(1-\alpha)\left[(1+r)\left(y L_{f}-T\right)+\Pi_{2} L_{f}\right]+\gamma G-\Pi_{2} L_{f} .
$$

Then,

$$
\begin{gathered}
\gamma(G-T)=\gamma(1-\alpha)\left(y L_{f}-T\right)-(1-\alpha)(1+r)\left(y L_{f}-T\right)-(1-\alpha) \Pi_{2} L_{f}-\alpha \gamma \frac{\Pi_{2} L_{f}}{1+r} \\
\quad+\Pi_{2} L_{f} \\
=\gamma\left[(1-\alpha)\left(y L_{f}-T\right)-\alpha \frac{\Pi_{2} L_{f}}{1+r}\right]-(1+r)\left[(1-\alpha)\left(y L_{f}-T\right)-\alpha \frac{\Pi_{2} L_{f}}{1+r}\right] .
\end{gathered}
$$

Therefore, 


$$
\begin{gathered}
\gamma(G-T)+r\left[(1-\alpha)\left(y L_{f}-T\right)-\alpha \frac{\Pi_{2} L_{f}}{1+r}\right]=\gamma\left[(1-\alpha)\left(y L_{f}-T\right)-\alpha \frac{\Pi_{2} L_{f}}{1+r}\right] \\
-\left[(1-\alpha)\left(y L_{f}-T\right)-\alpha \frac{\Pi_{2} L_{f}}{1+r}\right] .
\end{gathered}
$$

This means that the budget deficit including the interest payment for the government bonds equals the difference between the net savings of the younger generation consumers and that of the older generation consumers.

\section{References}

Hattori, M., \& Tanaka, Y. (2020). Divisibility of labour supply and involuntary unemployment: a perfect competition model. Journal of Economics and Management, 16, 193-206. [Online] Available:

https://jem.fcu.edu.tw/assets/jem/past_issues/vol.16_no.2/PDF/vol.16_no.2_05.pdf

Kelton, S. (2020). The Deficit Myth: Modern Monetary Theory and the Birth of the People's Economy. Public Affairs.

Lerner, A. P. (1943). Functional finance and the federal debt. Social Research, 10, 38-51.

Lerner, A. P. (1944). The Economics of Control: Principles of Welfare Economics. Macmillan.

Mitchell, W., Wray, L. R., \& Watts, M. (2019). Macroeconomics. Red Globe Press.

Mochizuki, S. (2020). A book understanding MMT (in Japanese, MMT ga yokuwakaru hon). Shuwa System.

Morinaga, K. (2020). MMT will save Japan (in Japanese, MMT ga nihon wo sukuu). Takarajimasha.

Nakano, A. (2020). A book to understand the key points of MMT (in Japanese, MMT no pointo ga yokuwakaru hon), Shuwa System.

Otaki, M. (2007). The dynamically extended Keynesian cross and the welfare-improving fiscal policy. Economics Letters, 96, 23-29. https://doi.org/10.1016/j.econlet.2006.12.005

Otaki, M. (2009). A welfare economics foundation for the full-employment policy. Economics Letters, 102, 1-3. https://doi.org/10.1016/j.econlet.2008.08.003

Otaki, M. (2015). Keynesian Economics and Price Theory: Re-orientation of a Theory of Monetary Economy. Springer. https://doi.org/10.1007/978-4-431-55345-8

Park, S. (2020). The fallacy of fiscal collapse (in Japanese, Zaisei hatanron no ayamari). Seitosha.

Shimakura, G. (2019). What is MMT? (in Japanese, MMT towa nanika), Kadokawa Shinsho.

Wray, L. R. (2015). Modern Money Theory: A Primer on Macroeconomics for Sovereign Monetary Systems (2nd ed.). Palgrave Macmillan. 


\section{Copyright Disclaimer}

Copyright for this article is retained by the author(s), with first publication rights granted to the journal.

This is an open-access article distributed under the terms and conditions of the Creative Commons Attribution license (http://creativecommons.org/licenses/by/4.0/). 